\title{
Evaluation of clinical prognostic factors in Polish interferon beta-1b treated multiple sclerosis patients
}

\author{
Anna Pietrzak ${ }^{1}$, Alicja Kalinowska-Łyszczarz ${ }^{2}$, Wojciech Kozubski ${ }^{1}$, Sławomir Michalak ${ }^{2}$ \\ ${ }^{1}$ Department of Neurology, Poznan University of Medical Sciences, Poznan, Poland \\ ${ }^{2}$ Department of Neurochemistry and Neuropathology, Department of Neurology, Poznan University of Medical Sciences, Poznan,
} Poland

\begin{abstract}
Introduction. Prompt successful control of disease activity in multiple sclerosis (MS) patients improves outcomes. Therefore, tools to aid drug selection and detect non-responders are urgently needed. Although several biochemical markers for predicting response to treatment have been proposed, clinical markers involving relapses, imaging activity and disability progression in the initial years of therapy remain competitive and appear cost-effective in a real-life setting. The aim of this study was to evaluate the prognostic value of select clinical scores in interferon beta-1b (IFN $\beta-1 b$ ) treated MS patients.

Materials and methods. Eighty-eight relapsing-remitting MS (RRMS) patients initiating treatment with IFN $\beta$-1b in a Polish outpatient clinic were followed for a median of 5.5 years. Rio, modified Rio and BREMSO scores, as well as two-year no evidence of disease activity (NEDA), were assessed as predictors of disease activity during the observation.

Results. A Rio score of 1 had a Positive Predictive Value (PPV) of $83.3 \%$ and a Negative Predictive Value (NPV) of $71.4 \%$ for the occurrence of relapses in the first five years. A Rio and modified Rio score of 1 was associated with MRI activity after year 3. A loss of NEDA within the first two years was associated with a failure to maintain NEDA in the next three years. The BREMSO score was higher in patients with early relapse activity. Only baseline EDSS and total number of pre-treatment relapses were significantly associated with disability progression.

Conclusions. Rio, modified Rio, early NEDA on treatment and BREMSO score are relatively specific, but insensitive, predictors of relapse activity in the first years of IFN $\beta-1 b$ treatment. Higher pre-treatment EDSS and relapse activity is associated with disability progression, but not overall NEDA, in subsequent observation. While none of the markers is sufficiently sensitive or specific to make a certain prognosis, they may aid treatment decisions in patients with continued early disease activity.
\end{abstract}

Key words: multiple sclerosis, interferon-beta, treatment outcome, Rio score, BREMSO, no evidence of disease activity (NEDA)

\section{Introduction}

Sustained disease activity is associated with worse shortand long-term outcomes in multiple sclerosis (MS) patients [1-3].

With the development of new, highly effective therapies, no evidence of disease activity (NEDA) has become the most widely accepted treatment target. Advances in pharmacotherapy allow us to achieve NEDA in a growing number of patients, although at the price of an increased risk of adverse effects $[4,5]$. At the same time, safer but possibly less effective first-line agents may be sufficient to control disease activity in select low-risk patients. Better ways of identifying such patients are urgently needed.

Interferon-beta (IFN $\beta$ ) continues to be widely used as a first-line disease modifying drug (DMD). Many prognostic markers for IFN $\beta$ response have been proposed, including clinical, imaging, biochemical and immunological parameters. Clinical and imaging markers have been the most studied and widely used. Among these, Rio score [6] and modified Rio score [7] have been specifically developed and validated for IFN $\beta$-treated patients. These scores allow for some disease activity in the responder group. On the other hand, maintenance 
of NEDA in the first two years of therapy has recently been suggested as a predictive marker and found to correlate with a lack of disability progression of up to seven years [8].

Another approach towards computing a prognostic score, the Bayesian Risk Estimate for MS (BREMS), comprises age, gender, initial relapse characteristics (motor, motor-sensory and/or sphincter involvement, number of functional systems affected, completeness of recovery), and events within the first year from disease onset (motor and sphincter relapse, reaching EDSS 4) [9]. BREMS was specifically developed to evaluate the risk of an unfavourable natural history of the disease. The BREMS score is significantly higher in untreated patients reaching secondary progressive MS within 10 years $[9,10]$. A simplified score omitting the first year's observation, namely BREMSO [10], has been shown to highly correlate to BREMS and to predict disease progression.

The aim of our study was to assess the value of scores allowing for minimal disease activity (Rio and modified Rio), a restrictive no-activity score (two-year NEDA), or a composite pre-treatment risk estimate (BREMSO), as predictive factors for treatment response in a Polish population of IFN $\beta-1 b$ treated RRMS patients.

\section{Materials and methods}

The study protocol was approved by the Internal Review Ethics Board of Poznan University of Medical Sciences. All patients gave written informed consent for study participation.

\section{Study group}

Eighty-eight treatment-naïve, adult, relapsing-remitting MS patients were recruited consecutively between 2008 and 2013 while initiated on IFN $\beta$ - $1 \mathrm{~b}$ treatment in the MS outpatient clinic by Heliodor Swiecicki University Hospital in Poznan, Poland. All patients met the revised $2010 \mathrm{McDonald}$ criteria for the diagnosis of RRMS [11]. The patients were treated within the setting of the Polish National Health Fund MS treatment programme, with eligibility criteria as outlined in Table 1.

\section{Treatment}

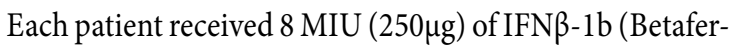
on, Bayer in 83 patients; or Extavia, Novartis in five patients) subcutaneously every other day.

\section{Follow-up}

Each patient was assessed monthly by a neurologist who recorded relapses and EDSS score changes.

A 1.5 Tesla brain magnetic resonance imaging (MRI, Siemens Avanto, Erlangen, Germany) with a 12-channel head coil, including T1, T2, Fluid Attenuated Inversion Recovery (FLAIR) and Proton Density (PD) sequences, with gadolinium contrast administration, was performed at baseline and repeated yearly. Spinal MRI was obtained when deemed necessary by the treating physician.
For each subsequent year, the number of relapses, active lesions on MRI, and change in EDSS were recorded, and NEDA status was determined for each subject.

\section{Scoring}

Rio score is calculated as described by Rio et al. [6], as the sum of the following three criteria assessed after the first year of therapy:

- MRI criterion $=1$; if $>2$ active MRI lesions (new or enlarging T2-weighted lesions, + the number of gadolinium-enhancing (Gd+) T1-weighted lesions on the yearly MRI scan);

- relapse criterion $=1$; if $\geq 1$ relapse;

- EDSS criterion $=1$; if an increase in EDSS score of $\geq 1$ point, sustained $\geq 6$ months and confirmed at the end of the follow-up period.

Modified Rio score [7] includes two criteria, scored after the first year of treatment:

- MRI criterion $=1$, if $>4$ new T2 lesions;

- relapse criterion $=1$ if 1 relapse occurred; $=2$ if $\geq 2$ relapses.

BREMSO score was computed as described previously [10], using the formula:

$-0.05 \times$ age (in decades)

$-\quad-1.07$ (if female gender)

- +0.93 (if sphincter onset)

- +0.62 (if pure motor onset)

- +0.81 (if motor and sensory onset)

- $+0.32 \times$ number of neurological functional systems involved at onset

- +0.52 (if incomplete recovery after onset)

No evidence of disease activity (NEDA) was defined as it has been previously [12]: within a given time window, NEDA means no relapses, no disability progression, and no MRI activity.

A relapse was defined as the emergence or worsening of symptoms applicable to multiple sclerosis, with focal neurological abnormality lasting 24 hours and preceded by $\geq 30$ days of stable neurological status, in the absence of fever or infection. Disability progression was scored after an increase in EDSS confirmed after 3 months: $\geq 1.5$ for a baseline score of 0 ; $\geq 1.0$ for scores from 1.0 to 5.0 ; and $\geq 0.5$ for baseline score of $\geq 5$.5. MRI activity was defined as new or enlarging lesions on T2/FLAIR or any contrast enhancing lesions.

\section{Statistical analysis}

P values of $\leq 0.05$ were considered statistically significant.

Variables were tested for normality of distribution and equality of variances with d'Agostino-Pearson's and Levene's tests. They were reported as means \pm standard deviations (SD) when normally distributed, or medians with interquartile ranges (IQR) otherwise.

Baseline characteristics were assessed for mutual correlations and compared to Rio, modified Rio, and BREMSO scores.

Associations were calculated between scale scores and outcomes (i.e. NEDA, relapse occurrence, disability 
Table 1. Eligibility criteria for Polish National Health Fund MS treatment programme 2008-2013

\begin{tabular}{|c|c|c|}
\hline Criterion & Before 2012 & Since 2012 \\
\hline Diagnosis & \multicolumn{2}{|c|}{ RRMS according to 2005 McDonald criteria AND contrast-enhanced head MRI consistent with MS } \\
\hline Disease activity & $\geq 2$ relapses within last two years & No criteria \\
\hline Required score & $\geq 21$ points & $\geq 15$ points \\
\hline \multirow[t]{21}{*}{ Scoring system } & Age (years): & Disease duration (years): \\
\hline & $16-40=6 \mathrm{pts}$ & $0-3=6 \mathrm{pts}$ \\
\hline & $40-60=3 \mathrm{pts}$ & $3-6=4$ pts \\
\hline & $>60=1 \mathrm{pt}$ & $6-10=2$ pts \\
\hline & Disease duration (years): & $>10=1 \mathrm{pt}$ \\
\hline & $0-3=6 \mathrm{pts}$ & No neurological deficit $=5 \mathrm{pts}$ \\
\hline & $3-6=3 \mathrm{pts}$ & Number of relapses in the last year: \\
\hline & $6-10=2$ pts & $\geq 3=5 \mathrm{pts}$ \\
\hline & $>10=1 \mathrm{pt}$ & $1-2=4$ pts \\
\hline & No neurological deficit $=5 \mathrm{pts}$ & none $=1 \mathrm{pt}$ \\
\hline & Number of relapses in the last year: & EDSS score: \\
\hline & $3-4=5 \mathrm{pts}$ & $0-2=6 \mathrm{pts}$ \\
\hline & $1-2=4$ pts & $2.5-4=5 \mathrm{pts}$ \\
\hline & $6-7=2 \mathrm{pts}$ & $4.5-5=2 \mathrm{pts}$ \\
\hline & none (less than $1 /$ year) $=1 \mathrm{pt}$ & $>5=1 \mathrm{pt}$ \\
\hline & $>7=0 \mathrm{pts}$ & \\
\hline & EDSS score: & \\
\hline & $0-2=6 \mathrm{pts}$ & \\
\hline & $2.5-4=3 \mathrm{pts}$ & \\
\hline & $4.5-5=2 \mathrm{pts}$ & \\
\hline & $>5=1 \mathrm{pt}$ & \\
\hline \multirow[t]{8}{*}{ Exclusion criteria } & 1. allergy to IFN $\beta$ & \\
\hline & 2. primarily or secondarily progressive MS & \\
\hline & 3. pregnancy & \\
\hline & 4. uncontrolled liver disease (aminotranferase levels $\geq 2 \times$ upp & \\
\hline & 5. uncontrolled thyroid disease (no euthyreosis) & \\
\hline & 6. a history of: & \\
\hline & 1. intractable depressive mood disorder or suicidal ideation; & \\
\hline & 2. epilepsy. & \\
\hline
\end{tabular}

MS - multiple sclerosis; RRMS - relapsing-remitting multiple sclerosis; MRI — magnetic resonance imaging; EDSS — Expanded Disability Status Score; pt — point

progression, MRI activity) in each subsequent year, for each period up to a subsequent year, after each subsequent year, and for the entire follow-up. The first year was excluded from correlations with first-year NEDA, Rio and modified Rio scores. Likewise the first two years were not considered for the correlations with second-year and two-year NEDA status or MRI activity.

The follow-up results were also assessed for correlations with other baseline characteristics.

Fisher's exact test was used for nominal and Mann-Whitney $\mathrm{U}$ test for ordinal variables. For interval variables, either a t-test or Mann-Whitney U test was employed, depending on the normality of distribution. For significant associations, sensitivity, specificity, positive predictive value (PPV) and negative predictive value (NPV) were determined. Receiver operating characteristic (ROC) curves were generated and areas under the curve (AUC) calculated for BREMSO.

Statistical analyses were performed using StatSoft STATISTICA version 13 [13] and MedCalc, version 15.8 [14].

\section{Results}

Patient characteristics, including demographics and treatment response

Eighty-eight patients ( 67 females, 21 males) were recruited for the study. Mean age at first relapse was $30.0 \pm 9.1$ years. It was higher in females $(31.3 \pm 9.6)$ than males $(25.9 \pm 5.3)$ $(p=0.002)$. There was no significant gender-specific difference in time to second relapse, time to treatment initiation, number of relapses before treatment, EDSS at baseline, or follow-up duration. Median delay from the first relapse to treatment 
onset was 18 months, and the median EDSS at treatment start was 1.0 (ranging from 0 to 4 , IQR $0-1.0$ ).

BREMSO scoring was possible in 80 patients, Rio score was obtainable in 50, and modified Rio in 50. Overall, 49 patients had both Rio and modified Rio, while 42 patients had all three scores. There was no statistically significant difference between these groups in baseline clinical features, including gender, age at first relapse, time to second relapse, time to treatment initiation, EDSS score, or relapses prior to treatment initiation.

The cohort was followed for a median of 5.5 years (range 0.4 to 9.2). Each year, between $60 \%$ and $80 \%$ of the patient cohort achieved NEDA (Fig. 1). In the first two years, relapses were the most common form of activity. Later, MRI activity predominated. In subsequent years, a cumulative loss of NEDA was observed.

During the follow-up, treatment was stopped in 51 patients. Until 2012, the Polish IFN treatment programme was limited to three years, and this was the sole reason for discontinuation in 14 cases $(27 \%)$. Five patients (10\%) either planned pregnancy or became pregnant. Thirteen patients switched DMD due to adverse effects (25\%), and in 14 (27\%) IFN $\beta$ - 1 b was deemed to be ineffective. Five patients (10\%) resigned for other reasons.

Among baseline clinical characteristics, in stepwise logistic regression, only pre-treatment EDSS score and total pre-treatment relapses were consistently correlated with outcome: higher EDSS scores were robustly associated with further disability progression in up to eight years of observation and NEDA loss in the first three years, while the number of relapses correlated with disability progression in the first six years. Considering the presence or absence of progression in the entire follow-up (regardless of its length), a significant association was found with both baseline EDSS and pre-treatment relapses.

A summary of the associations of the different scoring methods with disease activity during follow-up is presented in Table 2.

\section{Rio and modified Rio score over the first year of IFN $\beta$ - 1 b treatment}

Thirty-nine (78\%) patients had a Rio score of 0 , ten $(20 \%)$ had a score of 1 , and one case (2\%) was graded 2 . Forty-one $(82 \%)$ patients had a modified Rio score of 0 , eight $(16 \%)$ had a score of 1 , and one case (2\%) was graded 2 . In our cohort, Rio and modified Rio score were strongly correlated ( $\mathrm{p}<0.00001$; Rio and modified Rio score was different in three cases only).

There was no significant association between either Rio or modified Rio score and baseline clinical features, including pre-treatment EDSS and total number of relapses, age at first relapse, time to second relapse, or time to treatment onset.

Patients with scores $>0$ in the Rio scale were more likely to experience relapses up to the first 4-5 years of treatment. For modified Rio, a similar trend for the first four years was noted, but failed to reach statistical significance $(\mathrm{p}=0.066)$. No association with disability progression was present.

\section{BREMSO}

In the entire cohort, mean BREMSO score was 0.213 \pm 0.779 (median 0.350 with IQR -0.600 to 0.680 ). As expected, it was significantly higher in males (median 0.940 , IQR 0.420 to 1.350) than females (median -0.055 ; IQR -0.650 to 0.530 ; $\mathrm{p}<0.00001$ ). It was also weakly correlated with pre-treatment EDSS score (Kendall tau $=0.211 ; \mathrm{p}=0.049$ ).

BREMSO score was higher in patients with disease activity in the first year of treatment $(\mathrm{p}=0.035)$. It was also higher in patients with relapses in the first 2-3 years of treatment ( $p=0.048$ and 0.016 , respectively).

Exact values are shown in Table 3 (supplementary materials).

In ROC analysis, the criterion $>0.58$ had the highest combined sensitivity and specificity for both loss of NEDA in the first year and the occurrence of relapses within the first two or three years of treatment.

\section{Two-year NEDA}

Patients failing to maintain NEDA during the first two years of therapy were more likely to experience disease activity within the following 2-3 years, i.e. in years 3 to 4 and 3 to 5 of the follow-up. They were also more likely to have relapses in years 3 to 4 .

As the effect of IFN $\beta-1 b$ may not be apparent in the first six months of treatment, we also considered the prognostic value of NEDA in the second year alone. NEDA in year 2 conferred a significantly lower risk of relapses in year 3. No other statistically significant correlation with later disease course was observed. However, there was a trend $(\mathrm{p}=0.055)$ towards a lower risk of disability progression within the next four years (years 3 to 6 of the follow-up).

Meanwhile, a loss of NEDA during the first year correlated with higher risks of relapses and NEDA loss in years 2-4.

\section{Discussion}

To the best of our knowledge, this is the first study to have assessed the utility of Rio, NEDA and BREMSO as prognostic factors in a Polish population of IFN $\beta$-treated MS patients. Previously assessed were the baseline clinical features [15]: higher pre-treatment EDSS as well as higher annualised relapse ratio were associated with poor response at two and three years, respectively.

Our observations confirm and extend this observation, as higher pre-treatment EDSS and total number of relapses were associated with disability progression in our cohort, independently of other predictive factors. In fact, high baseline EDSS and early relapse activity have been consistently reported as the main negative prognostic factors in MS patients on DMDs [16-19].

In our cohort, Rio, early NEDA and BREMSO score were relatively specific, but insensitive, predictors of relapse activity in the first years of IFN $\beta$ - $1 \mathrm{~b}$ treatment. First two years NEDA and BREMSO also correlate with short-term NEDA. 


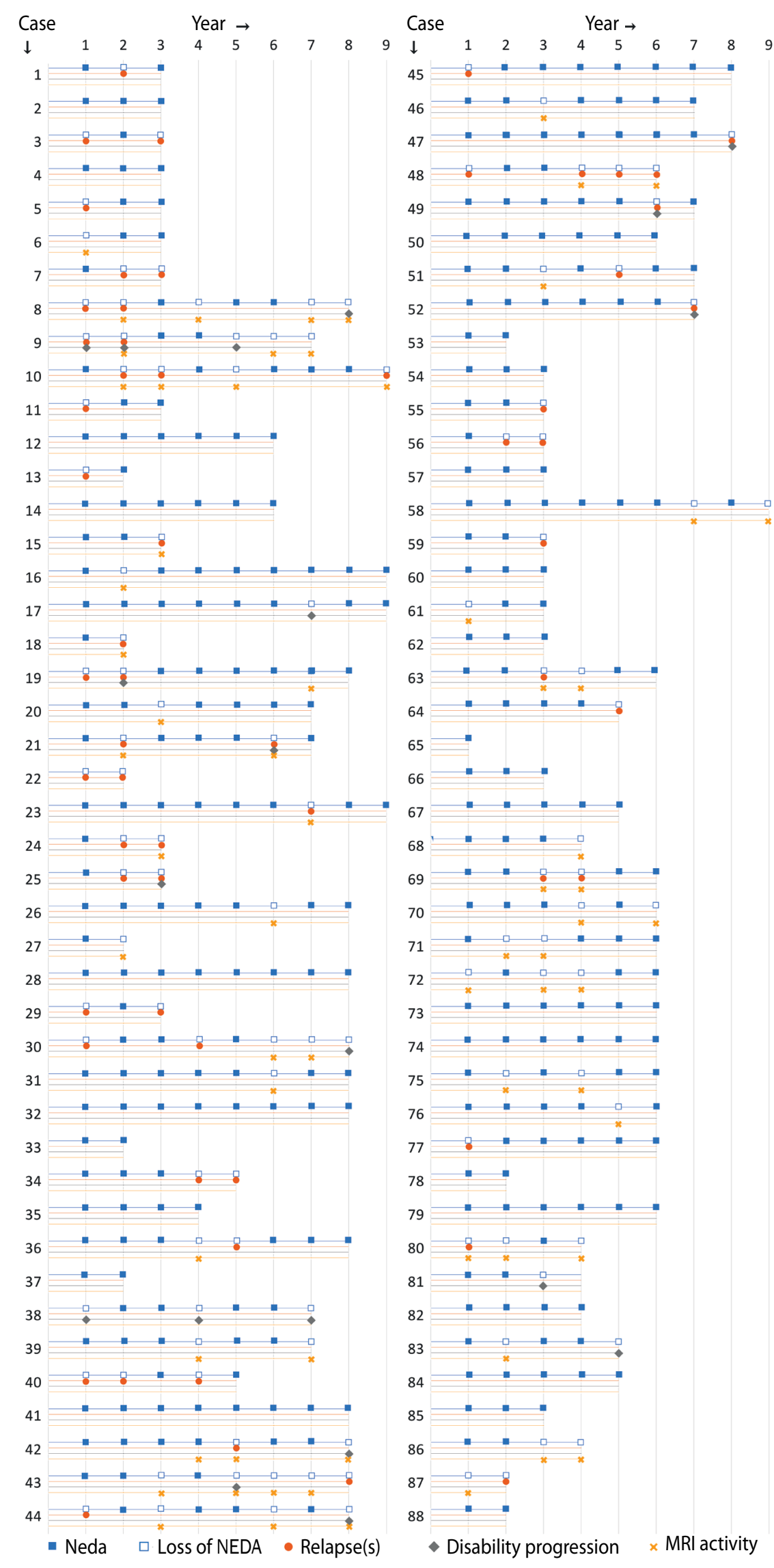

Figure 1. Disease activity, including NEDA status, relapse activity, disability progression and MRI activity, in the study cohort. Subsequent lines represent individual cases 
Table 2. Prognostic value of Rio, modified Rio, NEDA and BREMSO

\begin{tabular}{|c|c|c|c|c|c|}
\hline Parameter & $\begin{array}{l}\text { Fisher's } \\
\text { exact p }\end{array}$ & $\begin{array}{c}\text { Sensitivity [\%] } \\
(95 \% \mathrm{CI})\end{array}$ & $\begin{array}{c}\text { Specificity [\%] } \\
(95 \% \mathrm{CI})\end{array}$ & $\begin{array}{l}\text { PPV [\%] } \\
(95 \% \mathrm{CI})\end{array}$ & $\begin{array}{c}\text { NPV } \\
{[\%](95 \% \mathrm{CI})}\end{array}$ \\
\hline \multicolumn{6}{|l|}{ Rio score $>0$} \\
\hline $\begin{array}{l}\text { Relapses } \\
\text { in years } 2-4^{*}\end{array}$ & 0.016 & $\begin{array}{c}45.5 \\
(16.8-76.6 \%)\end{array}$ & $\begin{array}{c}92.3 \\
(74.9-99.1)\end{array}$ & $\begin{array}{c}71.4 \\
(29.0-96.3 \%)\end{array}$ & $\begin{array}{c}80 \\
(61.4-92.3 \%)\end{array}$ \\
\hline $\begin{array}{l}\text { Relapses } \\
\text { in years } 2-5^{*}\end{array}$ & 0.021 & $\begin{array}{c}38.5 \\
(13.9-68.4 \%)\end{array}$ & $\begin{array}{c}95.2 \\
(76.2-99.9 \%)\end{array}$ & $\begin{array}{c}83.3 \\
(35.9-99.6 \%)\end{array}$ & $\begin{array}{c}71.4 \\
(51.3-86.8 \%)\end{array}$ \\
\hline \multicolumn{6}{|c|}{ Loss of NEDA within first two years } \\
\hline $\begin{array}{l}\text { Loss of NEDA } \\
\text { in years 3-4 }\end{array}$ & 0.039 & $\begin{array}{c}50 \\
(30.7-69.4 \%)\end{array}$ & $\begin{array}{c}76.7 \\
(59.3-93.2 \%)\end{array}$ & $\begin{array}{c}70.8 \\
(48.8-90.9 \%)\end{array}$ & $\begin{array}{c}57.5 \\
(40.7-75.4 \%)\end{array}$ \\
\hline $\begin{array}{l}\text { Loss of NEDA } \\
\text { in years } 3-5\end{array}$ & 0.032 & $\begin{array}{c}50 \\
(33.4-66.6 \%)\end{array}$ & $\begin{array}{c}79.2 \\
(57.9-92.9 \%)\end{array}$ & $\begin{array}{c}79.2 \\
(57.9-92.9 \%)\end{array}$ & $\begin{array}{c}50 \\
(33.4-66.6 \%)\end{array}$ \\
\hline $\begin{array}{l}\text { Relapses } \\
\text { in years 3-4 }\end{array}$ & 0.035 & $\begin{array}{c}62.5 \\
(35.4-84.8 \%)\end{array}$ & $\begin{array}{c}70.2 \\
(55.1-82.7 \%)\end{array}$ & $\begin{array}{c}41.7 \\
(22.1-63.4 \%)\end{array}$ & $\begin{array}{c}84.6 \\
(69.5-94.1 \%)\end{array}$ \\
\hline \multicolumn{6}{|c|}{ Loss of NEDA in the first year } \\
\hline $\begin{array}{l}\text { Loss of NEDA } \\
\text { in years } 2-4\end{array}$ & 0.036 & $\begin{array}{c}31.8 \\
(18.6-47.6 \%)\end{array}$ & $\begin{array}{c}92 \\
(74.0-99.0 \%)\end{array}$ & $\begin{array}{c}87.5 \\
(61.7-98.5 \%)\end{array}$ & $\begin{array}{c}43.4 \\
(29.8-57.7 \%)\end{array}$ \\
\hline $\begin{array}{l}\text { Relapses } \\
\text { in years 2-4 }\end{array}$ & 0.017 & $\begin{array}{c}41.67 \\
(22.1-63.4 \%)\end{array}$ & $\begin{array}{c}86.1 \\
(72.1-94.7 \%)\end{array}$ & $\begin{array}{c}62.5 \\
(35.4-84.8 \%)\end{array}$ & $\begin{array}{c}72.6 \\
(58.3-84.1 \%)\end{array}$ \\
\hline \multicolumn{6}{|c|}{ Loss of NEDA in the second year } \\
\hline $\begin{array}{l}\text { Relapses } \\
\text { in year } 3\end{array}$ & 0.046 & $\begin{array}{c}50 \\
(30.7-69.4 \%)\end{array}$ & $\begin{array}{c}80 \\
(59.3-93.2 \%)\end{array}$ & $\begin{array}{c}31.3 \\
(11.0-58.7 \%)\end{array}$ & $\begin{array}{c}89.7 \\
(79.9-95.8 \%)\end{array}$ \\
\hline \multicolumn{6}{|l|}{ BREMSO (ROC analysis) } \\
\hline Parameter & $\begin{array}{c}\text { Criterion } \\
\text { (Youden index) }\end{array}$ & $\begin{array}{l}\text { Sensitivity [\%] } \\
(95 \% \mathrm{Cl})\end{array}$ & $\begin{array}{l}\text { Specificity [\%] } \\
\text { (95\% Cl) }\end{array}$ & $\begin{array}{c}\text { PPV } \\
\text { [\%] }(95 \% \mathrm{Cl})\end{array}$ & $\begin{array}{c}\text { NPV } \\
\text { [\%] }(95 \% \mathrm{Cl})\end{array}$ \\
\hline $\begin{array}{l}\text { Loss of NEDA } \\
\text { in year } 1\end{array}$ & $\begin{array}{l}>0.58 \\
(0.346)\end{array}$ & $\begin{array}{c}52.6 \\
(28.9-75.6)\end{array}$ & $\begin{array}{c}82.0 \\
(70.0-90.6)\end{array}$ & $\begin{array}{c}47.6 \\
(25.7-70.2)\end{array}$ & $\begin{array}{c}84.7 \\
(73.0-92.8)\end{array}$ \\
\hline $\begin{array}{l}\text { Relapses } \\
\text { in years 1-2 }\end{array}$ & $\begin{array}{l}>0.58 \\
(0.448)\end{array}$ & $\begin{array}{c}60 \\
(36.1-80.9)\end{array}$ & $\begin{array}{c}84.8 \\
(73.0-92.8)\end{array}$ & $\begin{array}{c}57.1 \\
(34.0-78.2)\end{array}$ & $\begin{array}{c}86.2 \\
(74.6-93.9)\end{array}$ \\
\hline $\begin{array}{l}\text { Relapses } \\
\text { in years 1-3 }\end{array}$ & $\begin{array}{l}>0.58 \\
(0.437)\end{array}$ & $\begin{array}{c}52.0 \\
(31.3-72.2)\end{array}$ & $\begin{array}{c}91.7 \\
(80.0-97.7)\end{array}$ & $\begin{array}{c}76.5 \\
(50.1-93.2)\end{array}$ & $\begin{array}{c}78.6 \\
(65.6-88.4)\end{array}$ \\
\hline
\end{tabular}

In the original report [6], a Rio score $\geq 2$ after one year of treatment predicted the occurrence of relapses or disability progression over two subsequent years, i.e. in years $2-3$. While a score of 1 was associated with an odds ratio of 1.4 for disease activity, it did not reach statistical significance. Modified Rio score was developed as a simplified but equally effective predictive marker [7]. A score $\geq 2$ identified non-responders, defined as patients with disability progression or $>1$ relapse, with PPV $=83 \%$ and NPV of $68 \%$. An analysis of the $\geq 2$ threshold was not possible in our study. Our cohort experienced a relatively mild first year of treatment, and so only a single patient scored 2 in Rio and another in modified Rio.

Nevertheless, the extended follow-up in our study revealed that even a Rio score $\geq 1$ confers an increased risk of disease activity, namely relapse occurrence in years 2-4. Meanwhile, the modified Rio score, omitting disability progression and allowing for more MRI activity, failed to predict disease activity in our patients. Neither Rio nor modified Rio correlated with disability progression.
A recent review [3] found that after the first year of treatment, alongside Rio score, the appearance of new T2 lesions has the highest predictive value for disability progression in subsequent years. In IFN-treated patients, new or enhancing lesions at first-year MRI scan were predictive of disability worsening both at short-term (two years, [20, 21], five years [22]) and in long-term observation (15-16 years, $[2,23])$. These observations contrast with the work of Goodin et al. [24], who found that no relapses and no EDSS worsening ('clinical NEDA') was just as good a predictor of future positive outcome as full NEDA, including lack of MRI activity. Our study was not designed to address the utility of MRI as a prognostic factor.

In our cohort, NEDA in the first two years had PPV of $50 \%$ and NPV of $79.2 \%$ for maintaining NEDA in years 3-5. Loss of NEDA in first two years was associated with increased risk of relapses in years 2-4.

On the other hand, we observed no correlation of NEDA status with disability progression. This may be caused by the adherence to NEDA-derived definition of disability 
Table 3. Statistically significant differences in BREMSO between patients with and without disease activity

\begin{tabular}{|c|c|c|c|c|c|c|}
\hline \multirow[t]{2}{*}{ Comparison } & \multicolumn{2}{|r|}{ Non-active } & & \multicolumn{2}{|r|}{ Active } & \multirow[t]{2}{*}{$\mathbf{p}$} \\
\hline & $\mathbf{N}$ & Mean \pm SD or median (IQR) & & $\mathbf{N}$ & Mean \pm SD or median (IQR) & \\
\hline \multicolumn{7}{|l|}{ BREMSO vs NEDA } \\
\hline in year 1 & 61 & $0.110 \pm 0.754$ & $<$ & 19 & $0.540 \pm 0.786$ & 0.035 \\
\hline \multicolumn{7}{|l|}{ BREMSO vs relapses } \\
\hline until year 2 & 59 & $0.123 \pm 0.736$ & $<$ & 20 & $0.519 \pm 0.842$ & 0.048 \\
\hline until year 3 & 48 & $0.045(-0.600$ to 0.475$)$ & $<$ & 25 & $0.680(-0.600$ to 1.102$)$ & 0.016 \\
\hline \multicolumn{7}{|c|}{ BREMSO vs progression } \\
\hline in year 5 & 44 & $0.02(-0.650$ to 0.480$)$ & $<$ & 3 & $0.540(0.533$ to 0.923$)$ & 0.044 \\
\hline \multicolumn{7}{|l|}{ BREMSO vs MRI } \\
\hline in year 5 & 42 & $-0.13(-0.650$ to 0.480$)$ & $<$ & 4 & $0.735(0.530$ to 1.170$)$ & 0.014 \\
\hline
\end{tabular}

$\mathrm{N}$ - number of cases; $\mathrm{SD}$ - standard deviation; IQR — interquartile range

progression. Arguably, outcome definitions have a large impact on conclusions drawn from observational studies. The maintenance of NEDA for the first two years of treatment was found to predict no disability progression, defined as no EDSS worsening of $\geq 0.5$ after seven years of follow-up in a mixedtreatment group [8]. In the randomised IFN $\beta-1 b$ trial, loss of NEDA status in the first two years predicted a poor outcome at 16 years, defined as progressive MS, the requirement for a wheelchair, or EDSS $\geq 6$ [24]. In addition, maintaining NEDA was associated with higher survival rates at 21 years.

These results underline the significance of early successful disease control for very long-term outcome measures.

While Rio and modified Rio scales are easy to calculate, and the concept of NEDA is uncomplicated, BREMSO score is a relatively complex Bayesian statistical model [10]. Even so, we decided to include it because unlike the aforementioned predictors, it does not require a treatment trial, potentially sparing the patient one or two years of ineffective therapy. As observational studies have consistently shown that a higher number of relapses in the first 2-5 years leads to faster disability accumulation and a higher probability of reaching secondary progression $[17-19,25]$, we believe that the use of more sophisticated predictive tools is well justified.

In our study, BREMSO pre-treatment score of $>0.58$ was moderately specific at predicting relapses in the first three years of therapy. It was also associated with loss of NEDA in the first year of treatment, but not in the subsequent observation. While BREMSO has been indicated as a prognostic marker in MS natural evolution [10], associations with disease progression were scant in our IFN $\beta$-treated cohort. BREMSO score was higher in patients with progression in the $5^{\text {th }}$ year $(\mathrm{p}=0.044)$, but the active group contained only three cases. BREMSO correlated marginally better with the final EDSS score (Kendall tau $=0.248 ; \mathrm{p}=0.021)$ than with pre-treatment EDSS.

Our study has several limitations. Complete follow-up data was not available in many patients: notably, a first-year MRI was performed in only half of the original cohort (for organisational and reimbursement reasons). Limited access to diagnostics and therapeutic programmes at the time of recruitment also explains the considerable (18 month) delay from the first relapse to treatment initiation. Numerous cases discontinued treatment throughout the study, lowering the statistical power in subsequent years of observation.

Overall, our results suggest that in IFN $\beta-1 b$ treated RRMS patients, any disease activity within the first two years of therapy (defined as loss of NEDA or $\geq 1$ point in Rio score) is associated with disease activity in the subsequent two or three years, predominately in the form of relapses.

For the prediction of relapses, compared to Rio score NEDA is slightly more sensitive, but this comes with a marked cost in specificity. BREMSO, as a pre-treatment assessment score, should therefore offer an advantage over Rio, because its associations with relapse activity were comparably specific and more sensitive, although they were limited to the first three years of treatment. For loss of NEDA, only early NEDA (in the first one or two years) appears to have any predictive value: the utility of BREMSO does not extend beyond the first year, possibly reflecting activity before IFN action onset as opposed to drug response. Rio score was not associated with NEDA or its components except for relapses.

In conclusion, none of the analysed factors is sensitive or specific enough to reliably classify patients as responders or non-responders. Disease activity prompting DMD change is associated with a loss of the early window of therapeutic opportunity in MS. In fact, it was recently shown that escalation strategies in real-world settings translate into faster disability progression than initial high-efficiency treatment [26]. Usually the progression had already occurred by the time DMD was switched, a clear indication that the decision was made too late.

Furthermore, with observational study design it is impossible to determine whether DMD switch would have any impact on the outcome, i.e. whether it was the severity of disease or poor drug activity that was to blame for the poor response.

Keeping the above in mind, we believe that further research should focus on: 
1) pre-treatment and on-treatment predictors of sustained good response that allow for the identification of patients in whom a low-potency DMD is likely to suffice;

2) pre-treatment predictors of poor response: here, a study design should target a benefit from treatment modification, rather than just a poor response to a given DMD.

Funding. This publication was prepared without any external source of funding.

Conflict of interest. The authors declare no conflict of interest related to the conduct of this study or the preparation of this manuscript.

WK reports no sponsorship related to this manuscript. AP has received travel compensation from Zentiva. AKL received grant funding from Novartis and received compensation for speaking and consulting services from Biogen, Bayer, Novartis, Roche, Merck, Teva, CSL Behring, Shire, and Sanofi-Genzyme. SM has received a travel grant from Bayer.

\section{References}

1. Dobson R, Rudick RA, Turner B, et al. Assessing treatment response to interferon- $\beta$ : is there a role for MRI? Neurology. 2014; 82(3): 248254, doi: 10.1212/WNL.00000000000000036, indexed in Pubmed: 24336144.

2. Bermel RA, You X, Foulds $P$, et al. Predictors of long-term outcome in multiple sclerosis patients treated with interferon $\beta$. Ann Neurol. 2013; 73(1): 95-103, doi: 10.1002/ana.23758, indexed in Pubmed: 23378325.

3. Río J, Ruiz-Peña JL. Short-term suboptimal response criteria for predicting long-term non-response to first-line disease modifying therapies in multiple sclerosis: A systematic review and meta-analysis. J Neurol Sci. 2016; 361: 158-167, doi: 10.1016/j.jns.2015.12.043, indexed in Pubmed: 26810535.

4. Pardo $G$, Jones DE, Pardo G, et al. The sequence of disease-modifying therapies in relapsing multiple sclerosis: safety and immunologic considerations. J Neurol. 2017; 264(12): 2351-2374, doi: 10.1007/s00415017-8594-9, indexed in Pubmed: 28879412.

5. Dörr J, Paul F. The transition from first-line to second-line therapy in multiple sclerosis. Curr Treat Options Neurol. 2015; 17(6): 354, doi: 10.1007/ s11940-015-0354-5, indexed in Pubmed: 25912246.

6. Río J, Castilló J, Rovira A, et al. Measures in the first year of therapy predict the response to interferon beta in MS. Mult Scler. 2009; 15(7): 848-853, doi: 10.1177/1352458509104591, indexed in Pubmed: 19542263.

7. Sormani MP, Rio J, Tintorè M, et al. Scoring treatment response in patients with relapsing multiple sclerosis. Mult Scler. 2013; 19(5): 605-612, doi: 10.1177/1352458512460605, indexed in Pubmed: 23012253.

8. Rotstein DL, Healy BC, Malik MT, et al. Evaluation of no evidence of disease activity in a 7-year longitudinal multiple sclerosis cohort. JAMA Neurol. 2015; 72(2): 152-158, doi: 10.1001/jamaneurol.2014.3537, indexed in Pubmed: 25531931.

9. Bergamaschi R, Quaglini S, Trojano M, et al. Early prediction of the long term evolution of multiple sclerosis: the Bayesian Risk Estimate for Multiple Sclerosis (BREMS) score. J Neurol Neurosurg Psychiatry. 2007; 78(7): 757-759, doi: 10.1136/jnnp.2006.107052, indexed in Pubmed: 17220286.

10. Bergamaschi R, Montomoli C, Mallucci G, et al. BREMSO: a simple score to predict early the natural course of multiple sclerosis. Eur J Neurol.
2015; 22(6): 981-989, doi: 10.1111/ene.12696, indexed in Pubmed: 25808578.

11. Polman $\mathrm{CH}$, Reingold $\mathrm{SC}$, Banwell $\mathrm{B}$, et al. Diagnostic criteria for multiple sclerosis: 2010 revisions to the McDonald criteria. Ann Neurol. 2011; 69(2): 292-302, doi: 10.1002/ana.22366, indexed in Pubmed: 21387374.

12. Kappos L, De Stefano N, Freedman MS, et al. Inclusion of brain volume loss in a revised measure of 'no evidence of disease activity' (NEDA-4) in relapsing-remitting multiple sclerosis. Mult Scler. 2016; 22(10): 1297-1305, doi: 10.1177/1352458515616701, indexed in Pubmed: 26585439.

13. TIBCO Software Inc. StatSoft STATISTICA 2017.

14. MedCalc Software bvba. MedCalc statistical software. Ostend, Belgium 2015. https://www.medcalc.org/ (13.05.2017).

15. Wawrzyniak S, Koziarska D, Kułakowska A, et al. Early predictors of injectable disease modifying drugs suboptimal response based on clinical and radiological data assessment in Polish Multiple Sclerosis patients. Neurologia i Neurochirurgia Polska. 2019; 53(2): 131-137, doi: 10.5603/pjnns.a2019.0010.

16. Zhornitsky S, Greenfield J, Koch MW, et al. Long-term persistence with injectable therapy in relapsing-remitting multiple sclerosis: an 18-year observational cohort study. PLoS One. 2015; 10(4): e0123824, doi: 10.1371/journal.pone.0123824, indexed in Pubmed: 25867095.

17. Weinshenker BG, RICE G, noseworthy JH, et al. The natural history of multiple sclerosis: a geographically based study. Brain. 1991; 114(2): 1045-1056, doi: 10.1093/brain/114.2.1045.

18. Confavreux C, Vukusic S, Adeleine P. Early clinical predictors and progression of irreversible disability in multiple sclerosis: an amnesic process. Brain. 2003; 126(Pt 4): 770-782, doi: 10.1093/brain/awg081, indexed in Pubmed: 12615637.

19. Scalfari A, Neuhaus A, Degenhardt A, et al. The natural history of multiple sclerosis: a geographically based study 10 : relapses and long-term disability. Brain. 2010; 133(Pt 7): 1914-1929, doi: 10.1093/brain/awq118, indexed in Pubmed: 20534650.

20. Río J, Rovira A, Tintoré M, et al. Relationship between MRI lesion activity and response to IFN-beta in relapsing-remitting multiple sclerosis patients. Mult Scler. 2008; 14(4): 479-484, doi: 10.1177/1352458507085555, indexed in Pubmed: 18562504.

21. Rudick RA, Lee JC, Simon J, et al. Defining interferon beta response status in multiple sclerosis patients. Ann Neurol. 2004; 56(4): 548-555, doi: 10.1002/ana.20224, indexed in Pubmed: 15389896.

22. Prosperini L, Gallo V, Petsas N, et al. One-year MRI scan predicts clinical response to interferon beta in multiple sclerosis. Eur J Neurol. 2009; 16(11): 1202-1209, doi: 10.1111/j.1468-1331.2009.02708.x, indexed in Pubmed: 19538207.

23. Hartung HP, Kieseier B, Goodin DS, et al. Variability in detection and quantification of interferon $\beta$ - $1 b$-induced neutralizing antibodies. J Neuroinflammation. 2012; 9: 129, doi: 10.1186/1742-2094-9-129, indexed in Pubmed: 22703536.

24. Goodin DS, Reder AT, Traboulsee AL, et al. IFNB Multiple Sclerosis Study Group and the 16- and 21-Year LTF Investigators. Predictive validity of NEDA in the 16- and 21-year follow-up from the pivotal trial of interferon beta-1b. Mult Scler. 2019; 25(6): 837-847, doi: 10.1177/1352458518773511, indexed in Pubmed: 29761737.

25. Leray E, Yaouanq J, Le Page E, et al. Evidence for a two-stage disability progression in multiple sclerosis. Brain. 2010; 133(Pt 7): 1900-1913, doi: 10.1093/brain/awq076, indexed in Pubmed: 20423930.

26. Harding $\mathrm{K}$, Williams 0 , Willis $\mathrm{M}$, et al. Clinical Outcomes of Escalation vs Early Intensive Disease-Modifying Therapy in Patients With Multiple Sclerosis. JAMA Neurol. 2019; 76(5): 536-541, doi: 10.1001/jamaneurol.2018.4905, indexed in Pubmed: 30776055. 